\title{
A Simulation Study on Reverse Jet During Air-core Vortex Formation
}

\author{
Fadhilah Mohd Sakri $^{\# 1}$, Mohd Amzar Azizan ${ }^{\# 2}$, Mohamad Fadzli Haniff ${ }^{* 3}$, Mohd Usairy Syafiq Sama'in

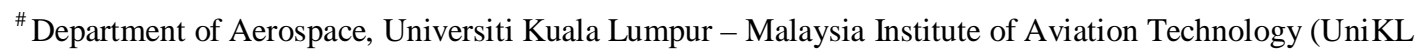 \\ MIAT), Jalan Jenderam Hulu, Kampung Jenderam Hulu, 43900 Sepang, Selangor, Malaysia \\ 1 fadhilahms@unikl.edu.my \\ 2 mohdamzar@unikl.edu.my \\ *Electrical, Electronics and Automation Section, Universiti Kuala Lumpur Malaysia - Spanish Institute (UniKL \\ MSI), Kulim Hi-Tech Park, 09000 Kulim Kedah, Malaysia \\ ${ }^{3}$ mohamadfadzli@unikl.edu.my \\ * Quality Engineering Section, Universiti Kuala Lumpur Malaysia - Institute of Industrial Technology (UniKL \\ MITEC), Bandar Seri Alam, 81750 Masai, Johor, Malaysia \\ 4usairy@unikl.edu.my
}

\begin{abstract}
The formation of air-core vortex is a common phenomenon during the draining process. However, there is an upward flow which is called as 'reverse jet' attempts during the air-core vortex formation. These phenomena if not properly controlled may reduce the efficiency and lifespan of liquid draining tank. Nevertheless, there is still no numerical research directed on the relation between air-core vortex and reverse jet, which might be very beneficial for the future study. Hence, the objective of this paper is to re revisits the fundamental physics flow of the reverse jet during the generation of air-core vortex. OpenFOAM®, an open source CFD package is used to simulate the flow inside the draining tank and the existence of reverse jet has been proved through the wake momentum thickness and Power-Spectral Density function (PSD).
\end{abstract}

Key words: Air-core vortex, reverse Jet, OpenFOAM, liquid draining.

\section{INTRODUCTION}

The formation of an air-core vortex inside the liquid draining tank is one of the problematic phenomenon during the draining process. Referring to Basu et al. [1], the air-core vortex is one of the rotational motions of the liquid, triggering air particles to be entrained in the vortex through its core. This motion is intensified by rotational (swirl) flow during the draining process [1]. When the core of the vortex touches the bottom of the tank, the draining rate of liquid decreases and the flow at the outlet nozzle becomes unsteady and highly rotational. However, an additional phenomenon called as 'reverse jet' is observed during the formation of aircore vortex. Reverse jet or reverse flow is a phenomenon, where the maximum velocity magnitude region is transferred to the center due to the evolution of the boundary layer on the side wall and the stability of angular momentum [2] [3].

The existence of air-core vortex and reverse jet affect the performance of the draining tank by inducing vibrations, increasing the possibility of structural damage, reducing the flow rate, reducing the efficiency and lifespan of pumps and turbines [2] [4] [7]. In aerospace application, the air-core vortex can distract the steady flow inside the pump during the liquid drainage from the propellant tanks of a space vehicle and rocket. Consequently, air is entrained into the propellant thereby reducing the liquid flow rate [8]. Therefore, to impede the over-rotational liquid motion and launch failure, the pump fed liquid rocket engines have to be cut off before the pressure gas enters the nozzle [1] [9]. In addition, the swirling flow in the reservoir tank due to the air-core vortex generation creates detrimental effects such as reduction in discharge coefficient, ingestion of floating objects and air entrainment that can affect machinery performance. There have also been accidents reported involving people getting sucked into the outlet (dam areas) due to the ingestion created by the air-core vortex [10].

Driven from the problems above, numerous studies by previous researchers have been done to minimize the effect of air-core vortex formation on structure [11][16]. However, there is still no numerical study conducted on the relation between air-core vortex and reverse jet, which might be very beneficial for the future research. As can be compared between other published numerical simulation methods [1] [3] [17][28], not much studies have been done using OpenFOAM, especially on reverse jet topic. Thus, the objective of this paper is to re revisits the fundamental physics flow of the reverse jet during the air-core vortex formation. 


\section{METHODOLOGY}

Figure 1 shows the schematic diagram of the problem geometry, where a cylindrical tank of length (L) of $450 \mathrm{~mm}$ and diameter (D) $90 \mathrm{~mm}$ is partially filled with water. The initial height of the water measured from the bottom of the tank $\left(\mathrm{h}_{\mathrm{o}}\right)$ is $350 \mathrm{~mm}$. A drain nozzle is located at the centre of the tank's bottom surface. The drain nozzle's length (1) is $15 \mathrm{~mm}$ and its diameter (d) is $6 \mathrm{~mm}$. The bottom and top surfaces of the tank is open, i.e., in atmospheric condition and the fluid is drained downward naturally by gravity, g. For direct comparisons to the study, this geometry is intentionally made the same as the experimental and numerical investigations of Park and Sohn (2011) [21] OpenFOAM $®$, an open source CFD package is used to simulate the flow inside the tank. Direct Numerical Simulation (DNS) is employed and the temporal term is discretized using the first-order scheme. Euler scheme (1st order accurate) has been adopted in the first stage. In second stage, it is changed to backward scheme (2nd order accurate) to reduce the discretization.

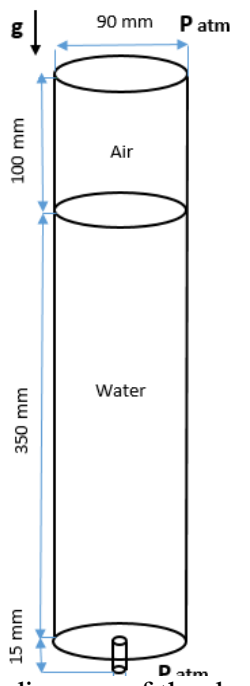

Figure 1: Schematic diagram of the draining tank [21]

\section{RESULTS AND DISCUSSIONS}

\subsection{Generation Air-core vortex}

Figure 2 shows the generation of the air core with a contact angle less than $90^{\circ}$ inside a cylindrical tank from $0 \mathrm{~s}$ to $82.5 \mathrm{~s}$. A dip is starting to develop on the free surface at the center of the tank at $15 \mathrm{~s}$. Then it is instantly dragged downwards and it quickly passes through the liquid inside the tank [11]. When the dip is extended till the outlet of the tank at the drain time of $21 \mathrm{~s}$, the air-core generation is completed. At this time, the dip grows into a vortex with the air core and the free surface generates a long and slender string shape lengthening to the bottom of the tank; this is known as a vortex (air-core) phenomenon [20]. The dip forms into the air-core on the surface as the level reaches a certain critical height $h_{c r}$ at which the liquid subsequently enters the outlet [1] and it constantly continues (except when the reverse jet is occurred) until the draining completes. However, in this study, the drain is turned suddenly and makes the induced oscillatory motion controls the forced motion. Thus, the reverse jet occurs 6 times along the draining process. They are at $22 \mathrm{~s}, 55 \mathrm{~s}, 72 \mathrm{~s}, 79.5 \mathrm{~s}, 80 \mathrm{~s}$ and 82 s.

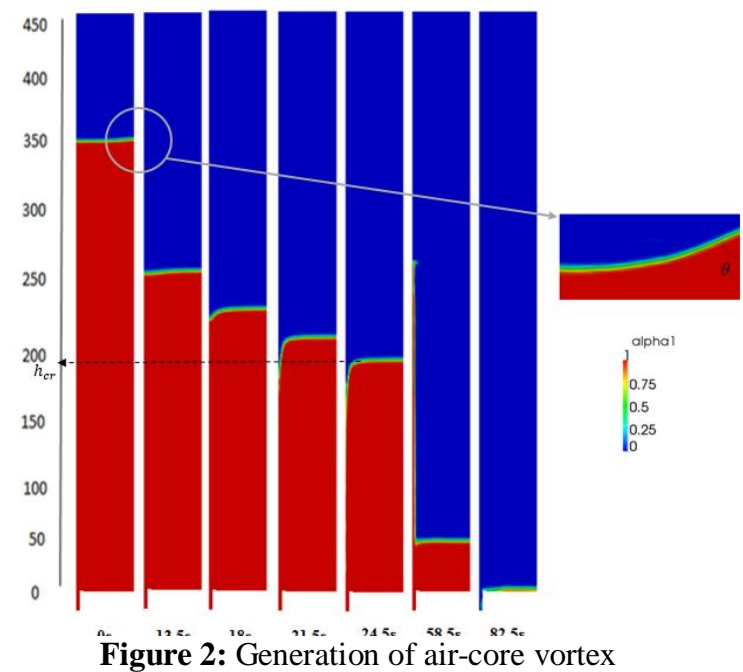

\subsection{Generation of Reverse Jet}

Figure 3 shows the free surface oscillation known as 'reverse jet' (reverse flow) which is only generated in the swirl case (without the air-core suppression mechanism) at $\mathrm{t}=58.5 \mathrm{~s}$. The formation of the aircore vortex is sustained and it is not disrupted by the reverse jet. The reverse jet arises on the liquid surface and at the same time allows the air (below the liquid surface) to be drained. The direction upward/downward of the reverse jet is based on the initial height of the free surface. Since the height of the liquid level at $\mathrm{t}=58.5 \mathrm{~s}$ and onwards are adequately low, the tip of the reverse jet moves upwards at each time. As a result of this condition, the region near the outlet promptly moves upwards, and this forms the reverse jet.

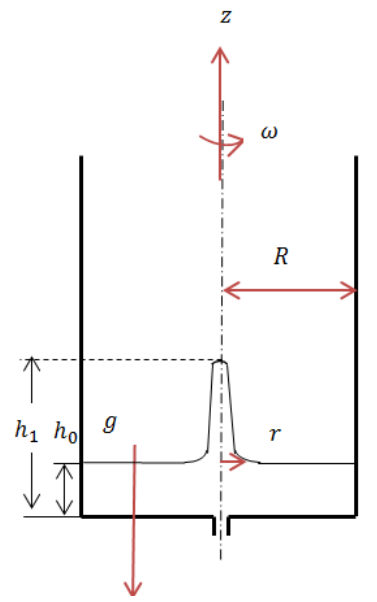

Figure 3: Generation of reverse jet at $t=58.5 \mathrm{~s}$ 
Referring to Barton et al. [29], the damping of free surface oscillations in the tank might occur along the draining process. In this study, a reverse flow (reverse jet) is observed even though the air-core is generated. The initial growth speed of the drainage-initiated free surface oscillations (reverse jet) is strongly influenced by the initial behavior of the drain rate function. So there is no reverse jet if the drain is turned on gradually, since the drainage-initiated free surface oscillation is weaker compared to the forced one [22]. According to Zhou and Graebel [22], a reverse jet occurs when the liquid is slowly drained with a constant drain rate in the center of the cylindrical tank. The strength of the reverse jet is determined by the initial height, $h_{o}$ of the free surface. The tip of the jet arises upwards from, $h_{o}$ and moves downwards from $h_{o}$. In this study, all of the reverse jets arise upwards since $h_{o}$ is adequately low at each time. Figure 4 shows the process of the generation of the reverse jet from $22 \mathrm{~s}$ to $24.5 \mathrm{~s}$.

Figure 5 shows the comparison of the velocity vector and streamlines between the drain times at $4 \mathrm{~s}$ (no reverse jet) and $23 \mathrm{~s}$ (reverse jet). In Figure 5(b), there is a clear upward flow (reverse direction to the flow) near the axis of the tank. According to Zhou and Graebel [22], it occurs when the nearest points to the surface center decelerate to the center and the maximum surface velocity is arisen on the free surface If the velocity is sufficiently large and the pressure is adequately low, the collection of fluid in that region is moves upwards [2]. The phenomenon can be proven and discussed through the characteristics of wake momentum thickness in the next section.

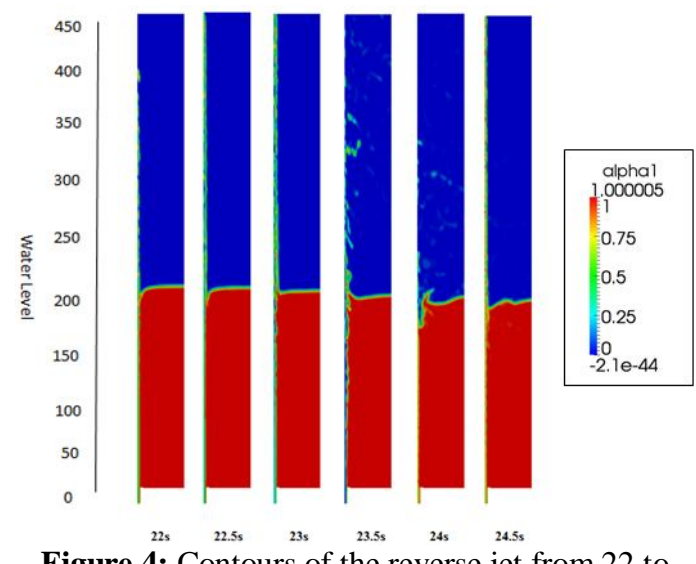

Figure 4: Contours of the reverse jet from 22 to $24.5 \mathrm{~s}$

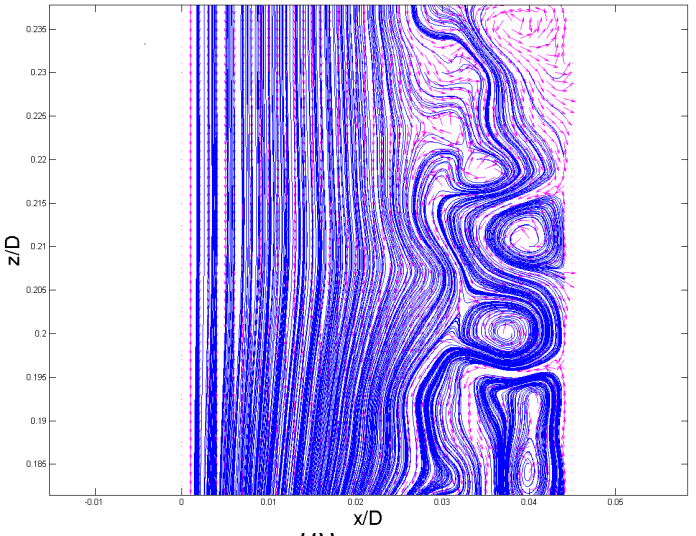

(d)

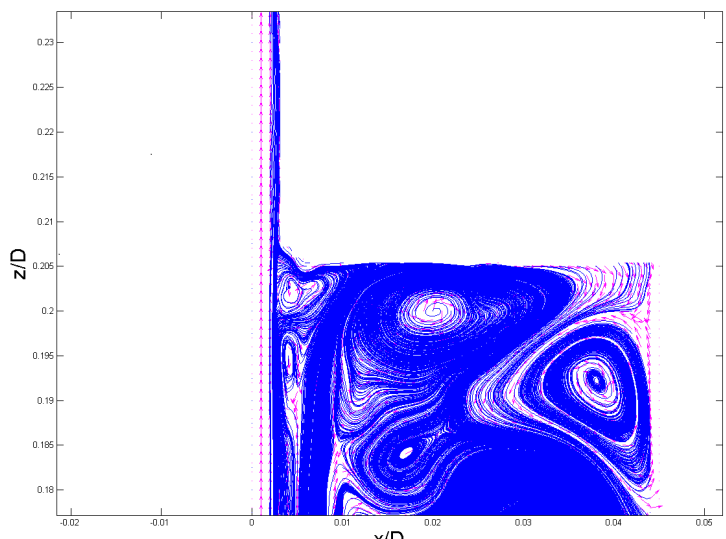

(b)

Figure 5: Comparison of velocity vector and streamlines between the drain times of (a) $t=4 \mathrm{~s}$ (no reverse jet) and (b) $t=23 \mathrm{~s}$ (reverse jet)

\subsection{Momentum Thickness}

Figure 6 represents the draining time at $\mathrm{t}=58 \mathrm{~s}, \mathrm{t}=$ $58.5 \mathrm{~s}, \mathrm{t}=59 \mathrm{~s}$ and $\mathrm{t}=59.5 \mathrm{~s}$ when the reverse jet occurs. In this research, the reverse jet is indentified by the characteristic of wake momentum thickness. As explained, the equation for the wake momentum thickness is $\theta_{m . t .} U_{\infty}^{2}=2 \int_{0}^{x_{\max }} \bar{u}\left(U_{\infty}-\bar{u}\right) d x$ where $\bar{u}$ is the time-averaged streamwise velocity in the $\mathrm{z}$ axis and $x$ is the localized cross-stream coordinate. The integral is defined from the center $(x=0)$ to the wall $(x=0.045)$ of the tank. Figure 6(b) shows the existence of wake momentum thickness since the reverse jet occurs at this time. Meanwhile, nearly zero magnitude of $\theta_{m . t}$ is observed at the center of the tank due to the formation of the air-core vortex. The air core reduces the efficiency of the outlet region, especially at the center of the tank. For the flow regime i.e. $0<R<0.45 \times 10^{-2}$, the highest magnitude of $\theta_{m . t}$ is observed. This condition happens because the location of the maximum velocity magnitude shifts to the center, and thus this area is instantly moved upwards (reverse jet). For the flow regime $0.45 \times 10^{-2}<R<0.045$, the magnitude of $\theta_{m . t .}$ decreases to the wall of the tank as the reverse jet starts to recover. 


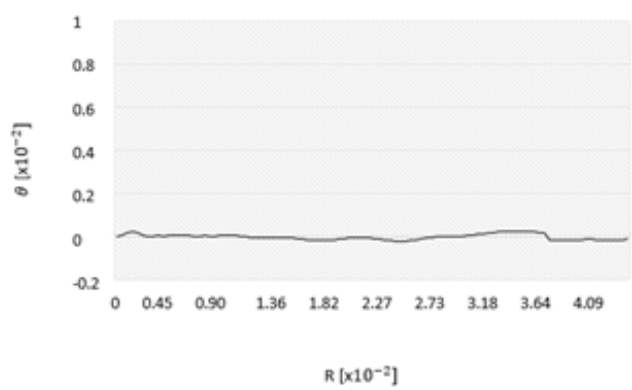

(a) $\mathrm{t}=58 \mathrm{~s}$

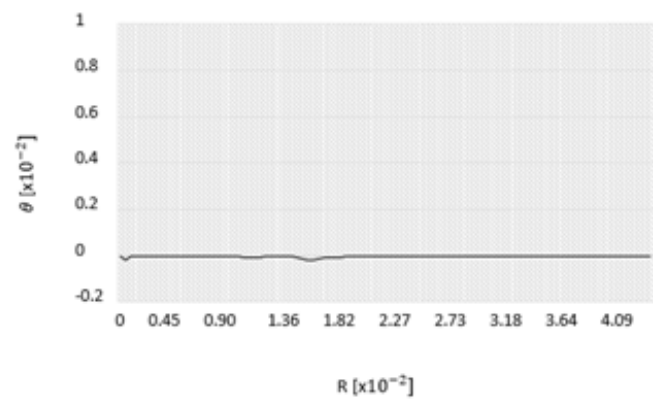

(c) $\mathrm{t}=59 \mathrm{~s}$

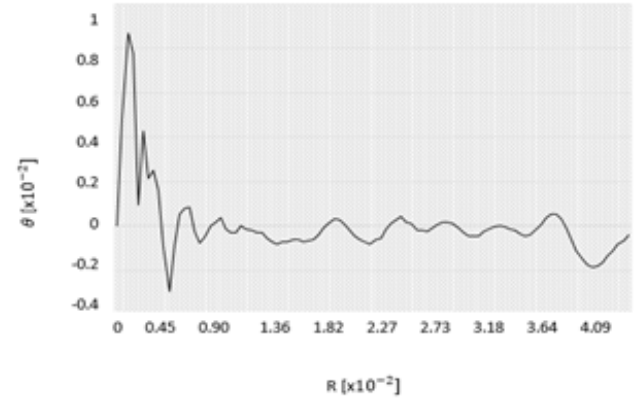

(b) $\mathrm{t}=58.5 \mathrm{~s}$

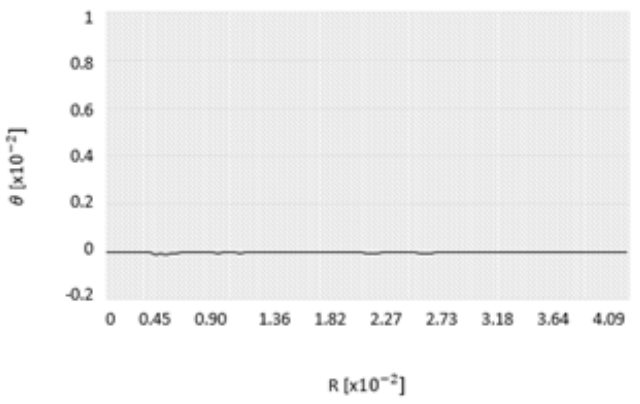

(d) $\mathrm{t}=59.5 \mathrm{~s}$

Figure 6: Momentum wake thickness $\left(\theta_{\text {m.t. }}\right.$ ) for various tank radius at $\mathrm{H}=215 \mathrm{~mm}$ : a) $\left.\left.\mathrm{t}=58 \mathrm{~s}, \mathrm{~b}\right) \mathrm{t}=58.5 \mathrm{~s}, \mathrm{c}\right)$ $\mathrm{t}=59 \mathrm{~s}$ and $\mathrm{d}) \mathrm{t}=59.5 \mathrm{~s}$

\subsection{Power Spectral Density (PSD)}

In this research, the fluctuating pressure fluctuating near the outlet and its power spectral density function (PSD) are presented in Figures 7 and 8. In Figure 8, the $x$-axis represents the frequency range and the $y$ axis shows the amplitude of power of pressure distribution. By looking at PSD, two sharp peaks marked by $*$ and $* *$ are observed. The sharp peak marked by $*$ is the highest peak. This peak has the frequency of $0.0928 \mathrm{~Hz}$ occurs at $\mathrm{t}=11 \mathrm{~s}$, which corresponds to the draining process from $48.5 \mathrm{~s}$ to $59.5 \mathrm{~s}$. In this time interval, the reverse jet occurs once at $58.5 \mathrm{~s}$. In addition, the other sharp peak marked by $* *$ has the frequency of $0.4455 \mathrm{~Hz}$ and occurs at $\mathrm{t}=$ $2.2 \mathrm{~s}$. The peak shows the draining process occurring from $79.5 \mathrm{~s}$ to $82.5 \mathrm{~s}$, and this period of time indicates the same phenomenon. Therefore, this result of PSD shows that the reverse jet phenomenon has a strong of frequency range variation that might be useful for further analysis.

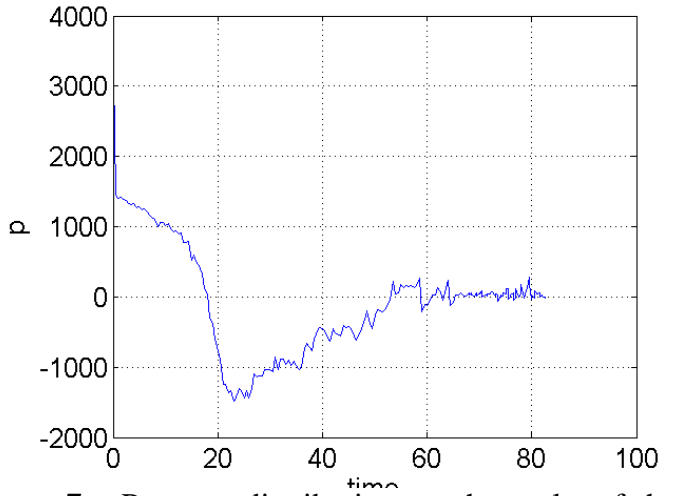

Figure 7: Pressure distributions at the outlet of the tank for the draining time 0 s to $82 \mathrm{~s}$

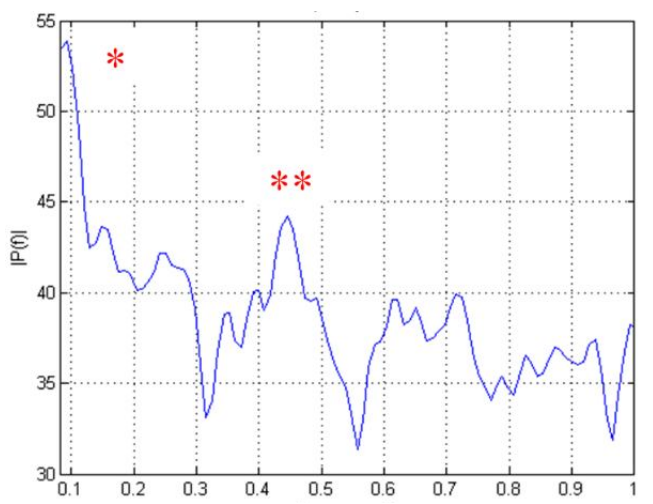

Figure 8: Power-spectral density function (PSD) for the pressure distributions at the outlet of the tank 


\section{CONCLUSION}

In this paper, the generation of air-core vortex and reverse jet were successfully recreated using the OpenFOAM framework. The phenomenon of reverse jet is observed in 6 times during the liquid draining process. A clear upward flow near the axis of the tank has been detected in the velocity vector and streamlines result. Finally, the presence of reverse jet during the air-core vortex formation has been proven through the existence of wake momentum thickness and Power-Spectral Density function (PSD).

\section{ACKNOWLEDGEMENT}

This research was financially supported by the Malaysian Ministry of Higher Education (MOHE) under the Research University Grant (RUG) project of Universiti Teknologi Malaysia FRGS Vote No. (4F712). The use of High-Performance Computer (HPC) at the Universiti Teknologi Malaysia facilities and the support from the Universiti Kuala Lumpur were also appreciated.

\section{REFERENCES}

[1] P.Basu, D. Agarwal, T. J. T. and A. Salih, "Numerical Studies on Air-core Vortex Formation During Draining of Liquids from Tanks," International Journal of Fluid Mechanics Research, vol. 40, no. 1, 2013. https://doi.org/10.1615/InterJFluidMechRes.v40.i 1.30

[2] Q. N. Z. Graebel and W. P., "Axisymmetric Draining of Cylindrical Tank with a Free Surface," Journal of Fluid Mechanics, vol. 221, pp. 511-532, 1990. https://doi.org/10.1017/S0022112090003652

[3] S. Mathew, B. Patnaik and T. J. Tharakan, "Numerical Study of Air-Core Vortex Dynamics During Liquid Draining From A Cylindrical Tanks," Fluids Dynamic Research, vol. 29, no. 10, p. 4247-4257, 2014.

[4] F. M. Sakri, M. S. M. Ali and S. A. Zaki, "Benchmark on the Dynamics of Liquid Draining Inside a Tank," E3S Web of Conferences , vol. 95, no. 02009, pp. 1-6, 2019.

[5] H. N. Abramson, W. H. Chu, L. R. G. Ransleben and G. E., "Some Studies of Liquid Rotation and Vortexing in Rocket Propellant," NASA D-1212, pp. 1-35, Feb. 1962.

[6] G. F. Parsley, "Propellant Vortexing in a Spinning Spacecraft," Journal of Spacecraft and Rockets, vol. 18, no. 5, pp. 418-426, 1981. https://doi.org/10.2514/3.28062

[7] J. T. Tharakan and K. Ramamurthi, "Shaped Discharge Ports for Draining Liquids," Journal of
Spacecraft and Rockets, vol. 30, no. 6, pp. 786788, 1992.

[8] C. H. Sohn, B. H. L. Gowda and M. G. Ju., "Eccentric Drain Port to Prevent Vortexing During Draining from Cylindrical Tanks," Journal of Spacecraft and Rockets, vol. 45, no. 3, 2008.

[9] K. Kinefuchi, ToruKamita and H. Negishi, "Experimental and Numerical Simulation Study of Liquid Propellant Draining from Rocket Tanks," Journal of Spacecraft and Rockets, vol. 47, no. 5, pp. 860-863, 2010.

[10 F. Trivellato, "Anti-vorticex Devices: Laser ] Measurements of the Flow and Functioning," Optics and Lasers in Engineering, vol. 48, pp. 589-599, 2010. https://doi.org/10.1016/j.optlaseng.2009.11.010

[11 J. H. Soon, C. H. Sohn and I. S. Park, "Numerical ] study of 3D Air-Core Phenomenon During Liquid Draining," Journal of Mechanical Science and Technology, vol. 29, no. 10, pp. 4247-4257, 2015.

[12 L. E., "Experiments on Unstable Vortices," ] Journal of the Engineering Mechanics Division, vol. 98, no. 3, pp. 539-559, 1972.

[13 G. Moller, "Vortex-Induced Air Entrainment ] Rates at Intakes," Mitteilugen, Zurich, 2013.

[14 L. H. J., Vortex Flow in the Nature and ] Technology, New York, USA: USA: Wiley, 1983.

[15 J. Knauss, "Swirling Flow Problems at Intakes,"

] A. A. Balkerma, Rotterdam, Netherland, 1987.

[16 E. Chang, "Riview of Literature on the Formation

] and Modelling of Vortices in Rectangular Pump Sump," Journal of Hydr. Res. , IAHR, vol. 16, 1978.

[17 F. M. Sakri, M. S. M. Ali, S. A. Z. S. Salim and

] M. A. Azizan, "Numerical study on air-core vortex inside draining tank using different computational modelling approaches," Jurnal Teknologi (Science \& Engineering), vol. 81, no. 1, pp. 1-9, 2019. https://doi.org/10.11113/jt.v81.11075

[18 F. M. Sakri, M. S. M. Ali and S. A. Z. S. Salim, "Numerical Simulation of Liquids Draining from a Tank Using OpenFOAM," IOP Conference Series: Materials Science and Engineering, vol. 226, no. 012152, 2017.

[19 F. M. Sakri, M. S. M. Ali and S. A. Z. S. Salim, ] "Computational investigations and grid refinement study of $3 \mathrm{D}$ transient flow in a cylindrical tank using OpenFOAM," IOP Conference Series: Materials Science and Engineering, vol. 152, no. 012058, 2016.

[20 S. C. Hyun, S. J. Hyeon and I. S. Park, ] "Numerical Analysis of Vortex Core Phenomenon During Draining from Cylinder Tank for Various Initial Swirling Speeds and 
Various Tank and Drain Port Sizes," Journal of Hydrodynamics, vol. 25, no. 2, pp. 183-195, 2013.

[21 I. S. Park and C. H. Sohn, "Experimental and

] Numerical Study on Air Cores for Cylindrical Tank Draining," International Communications in Heat and Mass Transfer, vol. 38, pp. 1044-1049, 2011.

[22 Q.-N. Zhou and W. Graebel, "Free Surface

] Oscillations in a Slowly Draining Tank," ASME, vol. 59, p. 438, 1992.

[23 J. Madsen, B. H. Hjertager and T. Solberg,

] "Numerical Simulation of Internal Flow in A Large-Scale Pressure-Swirl Atomizer," in ILASSS-Europe (Denmark), 2004.

[24 D. Agarwal, P. Basu, T. J. Tharakan and A. Salih,

] "Prediction of Gas-core Vortices During Draining of Liquid Propellants from Tanks," Aerospace Science and Technology, vol. 32, pp. 60-65, 2014.

[25 A. Robinson, H. Morvan and C. Eastwick,

] "Computational Investigations into Draining in an Axisymmetric Vessel," Journal of Fluids Engineering, vol. 132, 2010. https://doi.org/10.1115/1.4003151

[26 L. M. Rechiman, M. I. Centero and E. A. Dari,

] "Hydrodynamic Transient Assessment Of A Draining Tank," Mecanica Compuatational, vol. xxxiii, pp. 2927-2938, 2014.

[27 A. Z. a. M. S. N. Ibrahim, "Numerical

] Performance Evaluation of Savonius Rotors by Flow-driven and Sliding-mesh Approaches," International Journal of Advanced Trends in Computer Science and Engineering, vol. 8, no. 1, pp. 57-61, 2019.

https://doi.org/10.30534/ijatcse/2019/10812019

[28 L. N, V. K. Kumari, J. K, P. Nagamani and B. N.

] Kishore, "A Relative Study of Several Techniques for Underwater Image Improvement and Restoration," International Journal of Advanced Trends in Computer Science and Engineering, vol. 7, no. 6, pp. 115-119, 2018.

[29 Miles and J. W., "Note on The Damping of Free

] Surface Oscillations Due to Drainage," Journal of Fluid Mechanics, vol. 12, p. 438, 1962. https://doi.org/10.1017/S0022112062000324 